\title{
Activation of Transient Receptor Potential Vanilloid 4 Impairs the Dendritic Arborization of Newborn Neurons in the Hippocampal Dentate Gyrus through the AMPK and Akt Signaling Pathways
}

\begin{abstract}
Yujing Tian ${ }^{1+}$, Mengwen Qi't, Zhouqing Wang ${ }^{1}$, Chunfeng Wu ${ }^{2}$, Zhen Sun ${ }^{3}$, Yingchun $\mathrm{Li}^{1}$, Sha Sha ${ }^{1}$, Yimei Du ${ }^{4}$, Lei Chen ${ }^{1,5 *}$ and Ling Chen ${ }^{1}$

1 Department of Physiology, Nanjing Medical University, Nanjing, China, ${ }^{2}$ Department of Neurology, Children's Hospital of Nanjing Medical University, Nanjing, China, ${ }^{3}$ Department of Tangshan Branch, Jinling Hospital, Nanjing University, Nanjing, China, ${ }^{4}$ Research Center of Ion Channelopathy, Institute of Cardiology, Union Hospital, Tongji Medical College, Huazhong University of Science and Technology, Wuhan, China, ${ }^{5}$ Neuroprotective Drug Discovery Center, Nanjing Medical University, Nanjing, China
\end{abstract}

OPEN ACCESS

Edited by:

Oliver Stork,

Otto-von-Guericke University

Magdeburg, Germany

Reviewed by:

Christian Gonzalez-Billault,

Universidad de Chile, Chile

Jacek Jaworski,

International Institute of Molecular

and Cell Biology, Poland

*Correspondence:

Lei Chen

chen/@njmu.edu.cn

${ }^{\dagger}$ These authors have contributed equally to this work.

Received: 22 February 2017 Accepted: 29 May 2017

Published: 15 June 2017

Citation:

Tian Y, Qi M, Wang Z, Wu C, Sun Z,

Li Y, Sha S, Du Y, Chen L and

Chen L (2017) Activation of Transient Receptor Potential Vanilloid 4 Impairs the Dendritic Arborization of Newborn Neurons in the Hippocampal Dentate Gyrus through the AMPK and Ak Signaling Pathways.

Front. Mol. Neurosci. 10:190. doi: 10.3389/fnmol.2017.00190
Neurite growth is an important process for the adult hippocampal neurogenesis which is regulated by a specific range of the intracellular free $\mathrm{Ca}^{2+}$ concentration $\left(\left[\mathrm{Ca}^{2+}\right]_{\mathrm{i}}\right)$. Transient receptor potential vanilloid 4 (TRPV4) is a calcium-permeable channel and activation of it causes an increase in $\left[\mathrm{Ca}^{2+}\right]_{\mathrm{i}}$. We recently reported that TRPV4 activation promotes the proliferation of stem cells in the adult hippocampal dentate gyrus (DG). The present study aimed to examine the effect of TRPV4 activation on the dendrite morphology of newborn neurons in the adult hippocampal DG. Here, we report that intracerebroventricular injection of the TRPV4 agonist GSK1016790A for 5 days (GSK1016790A-injected mice) reduced the number of doublecortin immunopositive $\left(\mathrm{DCX}^{+}\right)$cells and $\mathrm{DCX}^{+}$fibers in the hippocampal DG, showing the impaired dendritic arborization of newborn neurons. The phosphorylated AMP-activated protein kinase ( $\mathrm{p}$-AMPK) protein level increased from $30 \mathrm{~min}$ to $2 \mathrm{~h}$, and then decreased from 1 to 5 days after GSK1016790A injection. The phosphorylated protein kinase B ( $p$-Akt) protein level decreased from 30 min to 5 days after GSK1016790A injection; this decrease was markedly attenuated by the AMPK antagonist compound $\mathrm{C}(\mathrm{CC})$, but not by the AMPK agonist AICAR. Moreover, the phosphorylated mammalian target of rapamycin (mTOR) and p70 ribosomal S6 kinase (p70S6k) protein levels were decreased by GSK1016790A; these changes were sensitive to $740 \mathrm{Y}-\mathrm{P}$ and $\mathrm{CC}$. The phosphorylation of glycogen synthase kinase $3 \beta$ (GSK3 $\beta$ ) at $Y^{216}$ was increased by GSK1016790A, and this change was accompanied by increased phosphorylation of microtubule-associated protein 2 (MAP2) and collapsin response mediator protein-2 (CRMP-2). These changes were markedly blocked by 740 Y-P and CC. Finally, GSK1016790A-induced decrease of $\mathrm{DCX}^{+}$cells and $\mathrm{DCX}^{+}$fibers was markedly attenuated by $740 \mathrm{Y}-\mathrm{P}$ and $\mathrm{CC}$, but 
was unaffected by AICAR. We conclude that TRPV4 activation impairs the dendritic arborization of newborn neurons through increasing AMPK and inhibiting Akt to inhibit the mTOR-p70S6k pathway, activate GSK3 $\beta$ and thereby result in the inhibition of MAP2 and CRMP-2 function.

Keywords: TRPV4, dendritic arborization, calcium, AMPK, Akt

\section{INTRODUCTION}

It has been proven that the mammalian brain continuously produces newborn neurons in the hippocampal dentate gyrus (DG) throughout adulthood (Alvarez-Buylla and GarciaVerdugo, 2002). Adult hippocampal neurogenesis is a complex process that begins with stem cells proliferation and followed by neuronal lineage specification, maturation, migration and incorporation into the hippocampal circuitry (Ge et al., 2008). Deficits in adult hippocampal neurogenesis can be seen in the pathogenesis of neurological diseases, including Alzheimer's disease (AD), Parkinson's disease (PD), depression and epilepsy (Balu and Lucki, 2009). Neurite growth is an important process in adult hippocampal neurogenesis and this process is crucial for the newborn neurons to establish new synaptic connections with the existing hippocampal circuitry by extending axonal and dendritic projections (Zhao et al., 2006). Neurite growth is regulated by a specific range of the intracellular free calcium concentration $\left(\left[\mathrm{Ca}^{2+}\right]_{\mathrm{i}}\right)$ (Mattson, 1987; Zheng, 2007; Toth et al., 2016). Sustained elevation of $\left[\mathrm{Ca}^{2+}\right]_{\mathrm{i}}$ inhibits growth cone advancement, and maximal neurite outgrowth occurred within an optimal range of $\mathrm{Ca}^{2+}$ concentrations (Tang and Dent, 2003). $\mathrm{Ca}^{2+}$ influx through $\mathrm{Ca}^{2+}$-permeable ion channels on the cell membrane or release from the intracellular $\mathrm{Ca}^{2+}$ stores can increase $\left[\mathrm{Ca}^{2+}\right]_{\mathrm{i}}$. In neurons, $\mathrm{Ca}^{2+}$ influx mainly occurs through voltage-gated calcium channels (VGCCs) and ligand-gated ion channels such as $N$-methyl-D-aspartate glutamate receptor (NMDAR), nicotinic acetylcholine receptor (nAChR), and transient receptor potential (TRP) channels (Pankratov and Lalo, 2014; Benemei et al., 2015). It has been reported that an L-type VGCC antagonist promotes axon outgrowth in dopaminergic brain slice co-cultures (Sygnecka et al., 2015). NMDAR has been proven to regulate neurite growth in the hippocampus (Nacher and McEwen, 2006). Activation of $\alpha 7 \mathrm{nAChR}$ significantly reduces axon growth in hippocampal neurons and thereby contributes to synaptic development and plasticity in the hippocampus (Nordman et al., 2014). Therefore, $\mathrm{Ca}^{2+}$-permeable channels may provide effective targets for the regulation of neurite growth.

The TRP channel family consists of several non-selective cationic channels that are sensitive to multiple physicochemical stimuli and capable of coupling their activity to downstream modulations of intracellular signals (Benemei et al., 2015). TRP vanilloid 4 (TRPV4) is a member of the vanilloid TRP subfamily (White et al., 2016). Activation of TRPV4 induces $\mathrm{Ca}^{2+}$ influx, which increases $\left[\mathrm{Ca}^{2+}\right]_{\mathrm{i}}$ in various cell types. It has been reported that TRPV4 mediates neurotrophic factorderived neuritogenesis in developing peripheral neurons (Jang et al., 2012). Some mutations in TRPV4 that augment $\mathrm{Ca}^{2+}$ influx have been shown to underlie the pathogenesis of TRPV4linked axonal neuropathies (Fecto et al., 2011). In our recent study, activation of TRPV4 promoted the proliferation of stem cells in the adult hippocampal DG (Tian et al., 2016). Whether activation of TRPV4 participates in the modulation of the neurite growth of newborn neurons in the hippocampal DG remains unclear. Activation of AMP-activated protein kinase (AMPK) has been shown to regulate the hippocampal neuronal structure (Ramamurthy et al., 2014). In addition to playing a pivotal role in modulating neuronal survival and differentiation, protein kinase $B$ (Akt) has recently emerged as an important regulator of neurite outgrowth (Read and Gorman, 2009). Activation of TRPV4 has been reported to modulate the AMPK and Akt signaling pathways in vitro (Hong et al., 2016). In the present study, we sought to determine whether TRPV4 activation affects the dendrite morphology of newborn neurons and further explored whether the AMPK or Akt signaling pathway is involved in TRPV4 action.

\section{MATERIALS AND METHODS}

\section{Experimental Animals}

Male mice (9-10 weeks old; ICR, Oriental Bio Service Inc., Nanjing, China) were used in the experiments. This study was approved by Animal Care and Ethical Committee of Nanjing Medical University. All animal experiments were conducted in accordance with the Guide for the Care and Use of Laboratory Animals of Nanjing Medical University. Animals were housed under standard conditions (room temperature $23 \pm 2{ }^{\circ} \mathrm{C}$, humidity $55 \pm 5 \%$ and $12: 12 \mathrm{~h}$ light/dark cycle) in the Animal Care Facility of Nanjing Medical University and were permitted free access to food and water. All efforts were made to minimize the animals' suffering and to reduce the number of animals used.

\section{Drug Treatment}

GSK1016790A is a synthetic agonist of TRPV4 and has been used to activate TRPV4 both in vivo and in vitro (Vincent and Duncton, 2011; Jie et al., 2015, 2016; Hong et al., 2016). AICAR is a commonly used and specific activator of AMPK, and compound C (CC) is a specific antagonist of AMPK (Han et al., 2005; Venna et al., 2012). 740 Y-P (or PDGFR ${ }^{740}$ Y-P) can bind with high affinity to p85 subunit of PI3K and has been widely used as a special agonist of PI3K (Derossi et al., 1998; Williams and Doherty, 1999). GSK1016790A, AICAR and 740 Y-P were administered by intracerebroventricular (icv) injections as described in previous reports (Han et al., 2005; Jie et al., 2015, 2016). Briefly, these drugs were injected into the right lateral 
ventricle $(0.3 \mathrm{~mm}$ posterior, $1.0 \mathrm{~mm}$ lateral, and $2.5 \mathrm{~mm}$ ventral to the bregma) using a stepper motor-controlled microsyringe (Stoelting, Wood Dale, IL, United States) at a rate of $0.2 \mu \mathrm{l} / \mathrm{min}$. The lateral ventricle within each cerebral hemisphere may communicate with the third ventricle through an interventricular foramen. To avoid the possible effect of these drugs on the left hippocampus, control mice were injected with the same volume of vehicle into the right lateral ventricle. It has been reported that CC showed neuronal protection in experimental stroke rodent models when it was administered intraperitoneally (ip) (Li J. et al., 2010; Liu et al., 2012; Venna et al., 2012). Therefore, in this study, CC was ip injected as previously reported (Li J. et al., 2010; Liu et al., 2012; Venna et al., 2012). GSK1016790A and CC were first dissolved in DMSO and then in $0.9 \%$ saline with a DMSO concentration of $1 \%$. GSK1016790A ( 0.1 to $5 \mu \mathrm{M} /$ mouse) was injected once daily for 5 days (GSK1016790A-injected mice). CC (10 mg/Kg), AICAR ( $2 \mathrm{mM} /$ mouse) or $740 \mathrm{Y}-\mathrm{P}(30 \mu \mathrm{M} / \mathrm{mouse})$ was injected $30 \mathrm{~min}$ before GSK1016790A injection and then injected once daily for 5 days. The concentrations of these drugs were chosen based on previous reports (Han et al., 2005; Li J. et al., 2010; Liu et al., 2012; Venna et al., 2012; Jie et al., 2015, 2016). The final volume was $2 \mu \mathrm{l}$ for icv and $0.2 \mathrm{ml}$ for ip injection. Control mice were injected with the same volume of vehicle. Each experimental group contained 9 mice.

\section{Histological Examination}

The mice were anesthetized with chloral hydrate $(400 \mathrm{mg} / \mathrm{kg}$, ip) and transcardially perfused with $4 \%$ paraformaldehyde 5 days after the beginning of the experiment (i.e., the first GSK1016790A injection). Brains were post-fixed overnight in 4\% paraformaldehyde at $4^{\circ} \mathrm{C}$ and coronally sectioned ( $40 \mu \mathrm{M}$ thick) using a vibrating microtome (Microslicer DTK 1500; Dousaka EM Co., Kyoto, Japan). For doublecortin (DCX) staining, freefloating sections were incubated with goat polyclonal anti-DCX antibody (1:500; Santa Cruz Biotechnology; Santa Cruz, CA, United States) overnight at $4^{\circ} \mathrm{C}$; they were then incubated with biotin-labeled rabbit anti-goat IgG antibody (1:200; Bioworld Technology, St. Louis Park, MN, United States) for $2 \mathrm{~h}$ at room temperature.

The DCX immunopositive $\left(\mathrm{DCX}^{+}\right)$cells in the sub-granular zone (SGZ) and $\mathrm{DCX}^{+}$fibers in the molecular layer (ML) of the hippocampal DG were counted using a conventional light microscope (Olympus DP70, Tokyo, Japan) with an oil immersion lens $(100 \times)$ and analyzed with the Image J software (NIH Image, Bethesda, MD, United States) (Wang et al., 2015). The $\mathrm{DCX}^{+}$cells were expressed as the number of $\mathrm{DCX}^{+}$cells per mm length along SGZ (Wang et al., 2015). The number of DCX ${ }^{+}$ fibers within $1 \mathrm{~mm}$ length was divided by the number of $\mathrm{DCX}^{+}$ cells. The number of $\mathrm{DCX}^{+}$fibers in the middle third of the ML $(\mathrm{Mm})$ stands for the density of dendrite and that in the outer third of the ML (Mo) stands for the length of dendrite (Sha et al., 2013; Wang et al., 2015).

\section{Western Blot Analysis}

After the mice were decapitated under deep anesthesia with ethyl ether, the hippocampi were quickly removed. The hippocampal protein concentrations were determined using a
BCA Protein Assay Kit (Pierce, Rochford, IL, United States). Equal levels of protein were separated by SDS-polyacrylamide gel electrophoresis and transferred to PVDF membranes. The membranes were blocked using 5\% non-fat milk in Tris-buffered saline (TBS)/Tween-20 and then incubated with antibodies against phospho-AMPK (p-AMPK, 1:1000, Cat\# 2531, Cell Signaling Technology, Beverly, MA, United States), phospho-Akt (p-Akt, 1:1000, Cat\# 4060, Cell Signaling Technology, Beverly, MA, United States), phospho-mammalian target of rapamycin (p-mTOR, 1:1000, Cat\# ab109268, Abcam, Cambridge, United Kingdom), phospho-p70 ribosomal S6 kinase (p-p70S6k, 1:1000, Cat\# 9205, Cell Signaling Technology, Beverly, MA, United States), phospho-glycogen synthase kinase $3 \beta$ (p-GSK3 $\beta$, 1:1000, Cat\# 612313, BD Bioscience, San Jose, CA, United States), phospho-microtubule-associated protein 2 (p-MAP2, 1:1000, Cat\# 4544, Cell Signaling Technology, Beverly, MA, United States), phospho-collapsin response mediator protein-2 (p-CRMP-2, 1:1000, Cat\# ab129066, Abcam, Cambridge, United Kingdom) and glyceraldehyde-3-phosphate dehydrogenase (GAPDH, 1:5000, Cat\# ab181602, Abcam, Cambridge, United Kingdom) at $4^{\circ} \mathrm{C}$ overnight. After being washed with TBST, the membranes were incubated with HRP-labeled secondary antibody, developed using an ECL Detection Kit (Amersham Biosciences, Piscataway, NJ, United States) and analyzed using Image J software (NIH). Following visualization of $\mathrm{p}$-AMPK, p-Akt, p-mTOR, p-p70S6k, p-GSK3 $\beta$, p-MAP2, and p-CRMP-2, the blots were stripped by incubation in stripping buffer (Restore, Pierce Chemical Co, Rockford, IL, United States) for $5 \mathrm{~min}$, re-blocked for 60 min with skim milk at room temperature, and then incubated with AMPK (1:1000, Cat\# 2532, Cell Signaling Technology, Beverly, MA, United States), Akt (1:1000, Cat\# 9272, Cell Signaling Technology, Beverly, MA, United States), mTOR, (Cat\# 2972, Cell Signaling Technology, Beverly, MA, United States), p70S6k (1:1000, Cat\# 2708, Cell Signaling Technology, Beverly, MA, United States), GSK3 $\beta$ (1:1000, Cat\# ab32391, Abcam, Cambridge, United Kingdom), MAP2 (1:1000, Cat\# 8707, Cell Signaling Technology, Beverly, MA, United States) and CRMP-2 (1:1000, Cat\# ab129082, Abcam, Cambridge, United Kingdom) antibodies, respectively. Hippocampal samples collected from the hemispheres of three mice were considered a set for western blot analysis. The data represent the average of three experimental sets. Western blot analysis for the p-AMPK, AMPK, p-Akt and Akt protein levels was performed at $30 \mathrm{~min}$, $2 \mathrm{~h}, 1$ and 5 days after the beginning of the experiment, and the analysis of the p-mTOR, mTOR, p-p70S6k, p70S6k, p-GSK3 $\beta$, GSK3 $\beta$, p-MAP2, MAP2, p-CRMP-2, and CRMP-2 protein levels was performed 5 days after the beginning of the experiment.

\section{Chemicals}

All chemicals, unless otherwise stated, were obtained from Sigma-Aldrich Co.

\section{Data Analysis}

Data are expressed as the mean \pm S.E.M, and statistical analyses were performed using SPSS software, version 16.0 (SPSS Inc., United States). ANOVA followed by Bonferroni's post hoc test was used to evaluate the statistical significance, and the significance 
level was set at $p<0.05$ and $p<0.01$. The protein levels of p-AMPK, p-Akt, p-mTOR, p-p70S6k, p-GSK3 $\beta$, p-MAP2, and p-CRMP-2 were first normalized to the protein level of AMPK, Akt, mTOR, p70S6k, GSK3 $\beta$, MAP2, and CRMP-2, respectively. The protein levels in mice injected with GSK1016790A and/or the kinase antagonist (agonist) were expressed as the percentage of that in vehicle-injected mice (control mice). The decrease in the number of $\mathrm{DCX}^{+}$fibers in Mm resulting from different doses of GSK1016790A was first normalized to the decrease caused by $10 \mu \mathrm{M} / \mathrm{mouse}$ GSK1016790A. The dose-response curve was fitted by the Hill equation, $a=a_{\max } /\left[1+\left(\mathrm{EC}_{50} / \mathrm{C}\right)^{n}\right]$, where $n$ is the Hill coefficient and the $\mathrm{EC}_{50}$ value is the dose of GSK1016790A that produced a 50\% effect.

\section{RESULTS}

\section{Effect of the TRPV4 Activation on the Dendritic Arborization of Newborn Neurons in the Hippocampal DG}

Doublecortin, a microtubule-associated protein, is specifically expressed in newly generated neurons, with peak expression during the 2nd week after their birth (Rao and Shetty, 2004; Duan et al., 2008; Wang et al., 2015). In the present study, the administration of the TRPV4 agonist GSK1016790A for 5 days significantly decreased the number of $\mathrm{DCX}^{+}$cells in the SGZ (Figures 1A,B), indicating that activation of TRPV4 may impair the newly generated neurons. $\mathrm{DCX}^{+}$cells extend their dendrites in the direction of the ML (Rao and Shetty, 2004). The ML of the DG was divided into the inner (Mi), middle $(\mathrm{Mm})$ and outer (Mo) subregions as previously reported (Wang et al., 2015; Figure 1A). The number of $\mathrm{DCX}^{+}$fibers in the Mm subregion was lower in GSK1016790A-injected mice than in the control group $(p<0.01)$. At doses ranging from 0.1 to $10 \mu \mathrm{M} /$ mouse, the number of $\mathrm{DCX}^{+}$fibers in the $\mathrm{Mm}$ subregion was dose-dependently decreased by GSK1016790A, and the values of the Hill coefficient and the $\mathrm{EC}_{50}$ were 1.37 and $0.54 \pm 0.14 \mu \mathrm{M} /$ mouse, respectively (Figures 1A,C,D). After the administration of $1 \mu \mathrm{M} /$ mouse GSK1016790A, the number of $\mathrm{DCX}^{+}$fibers in the Mm subregion decreased by $47.69 \pm 2.70 \%$ $(p<0.01)$, and this dose was used in the subsequent experiments. Compared to the control value, the number of $\mathrm{DCX}^{+}$fibers in the Mo subregion was also significantly reduced in GSK1016790Ainjected mice $(p<0.01)$. These results indicate that activation of TRPV4 impairs the dendritic arborization of newborn neurons.

\section{Effect of TRPV4 Activation on the AMPK and Akt Signaling Pathways}

We previously reported that acute activation of TRPV4 affected the AMPK-Akt signaling, which may be related to the TRPV4mediated $\mathrm{Ca}^{2+}$ influx (Hong et al., 2016). In this study, GSK1016790A was consecutively administered for 5 days and the changes in the protein levels of $\mathrm{p}$-AMPK and $\mathrm{p}$-Akt at different time points after GSK1016790A injection were examined. As shown in Figure 2, the protein levels of p-AMPK were $172.43 \pm 6.07 \%(p<0.01), 147.69 \pm 3.78 \%(p<0.01)$,
$53.54 \pm 5.57 \%(p<0.01)$, and $58.80 \pm 4.89 \%(p<0.01)$ of the control value at $30 \mathrm{~min}, 2 \mathrm{~h}, 1$ and 5 days after the beginning of the experiment, respectively (Figure 2A). This result indicates that AMPK activity may enhance within $2 \mathrm{~h}$ after TRPV4 activation and then decrease from 1 to 5 days after TRPV 4 activation. Unlike the changes in the $\mathrm{p}$-AMPK protein level, the protein levels of p-Akt were $69.35 \pm 5.67 \%(p<0.01), 46.85 \pm 3.47 \%(p<0.01)$ $49.25 \pm 5.11 \%(p<0.01)$, and $50.79 \pm 7.78 \%(p<0.01)$ of that in the control group at $30 \mathrm{~min}, 2 \mathrm{~h}, 1$ and 5 days after the beginning of the experiment, respectively (Figure 2B). This result indicates that Akt activity decreases upon TRPV4 activation. In order to examine whether AMPK was involved in GSK1016790Ainduced inhibition of p-Akt protein level, two time points, $2 \mathrm{~h}$ and 5 days after the beginning of the experiment were selected, because at these two time points, AMPK activity was differently modulated by GSK1016790A. Therefore, AMPK antagonist CC and AMPK agonist AICAR was used to examine whether they could affect GSK1016790A-decreased p-Akt protein level at $2 \mathrm{~h}$ and 5 days after the beginning of the experiment, respectively. Notably, the decrease in the p-Akt protein level at $2 \mathrm{~h}$ after the beginning of the experiment was markedly attenuated by CC. The p-Akt protein level at 5 days after the beginning of the experiment was the same as that in the mice that were co-injected with GSK1016790A and AICAR (Figure 2C). These results indicate that upon chronic TRPV4 activation, downregulated Akt signaling occurs most likely due to the activation of AMPK.

\section{Effect of TRPV4 Activation on Akt-related Signaling Pathways}

Akt plays an important role in modulating neurite outgrowth, which is mediated through downstream signals, such as mTOR and GSK3 $\beta$ (Read and Gorman, 2009). In this study, the number of $\mathrm{DCX}^{+}$fibers reduced after administration of GSK1016790A for 5 days. Additionally, Akt activity consistently decreased from $30 \mathrm{~min}$ to 5 days after the beginning of the experiment. The following experiments were performed 5 days after the beginning of the experiment to further explore the effect of TRPV4 activation on the downstream signals of Akt. Here, the protein level of p-mTOR in GSK1016790A-injected mice was $64.11 \pm 3.93 \%$ of that in the control group $(p<0.01)$ (Figure 3A). Moreover, the phosphorylation of p70S6k (p-p70S6k), a substrate of mTOR, was also lower than that of the control value (Figure 3B). As shown in Figure 3, the decreased protein levels of p-mTOR and p-p70S6k in GSK1016790A-injected mice were markedly reversed by the administration of the PI3K agonist 740 Y-P or the AMPK antagonist CC $(p<0.01$ in each group).

GSK3 $\beta$ is another key substrate of Akt that is critical for the specifying the axon/dendrite fate via its regulation of MAP2 and CRMP-2. As shown in Figure 4A, the phosphorylation of GSK3 $\beta$ at $\mathrm{Y}^{216}$ (p-GSK3 $\beta$ ) in GSK1016790A-injected mice was markedly higher than that in the control group $(p<0.01)$. Meanwhile, the phosphorylated MAP2 (p-MAP2) and CRMP-2 (p-CRMP-2) protein levels in GSK1016790A-injected mice were markedly higher than the control values ( $p<0.01$ in each group) 

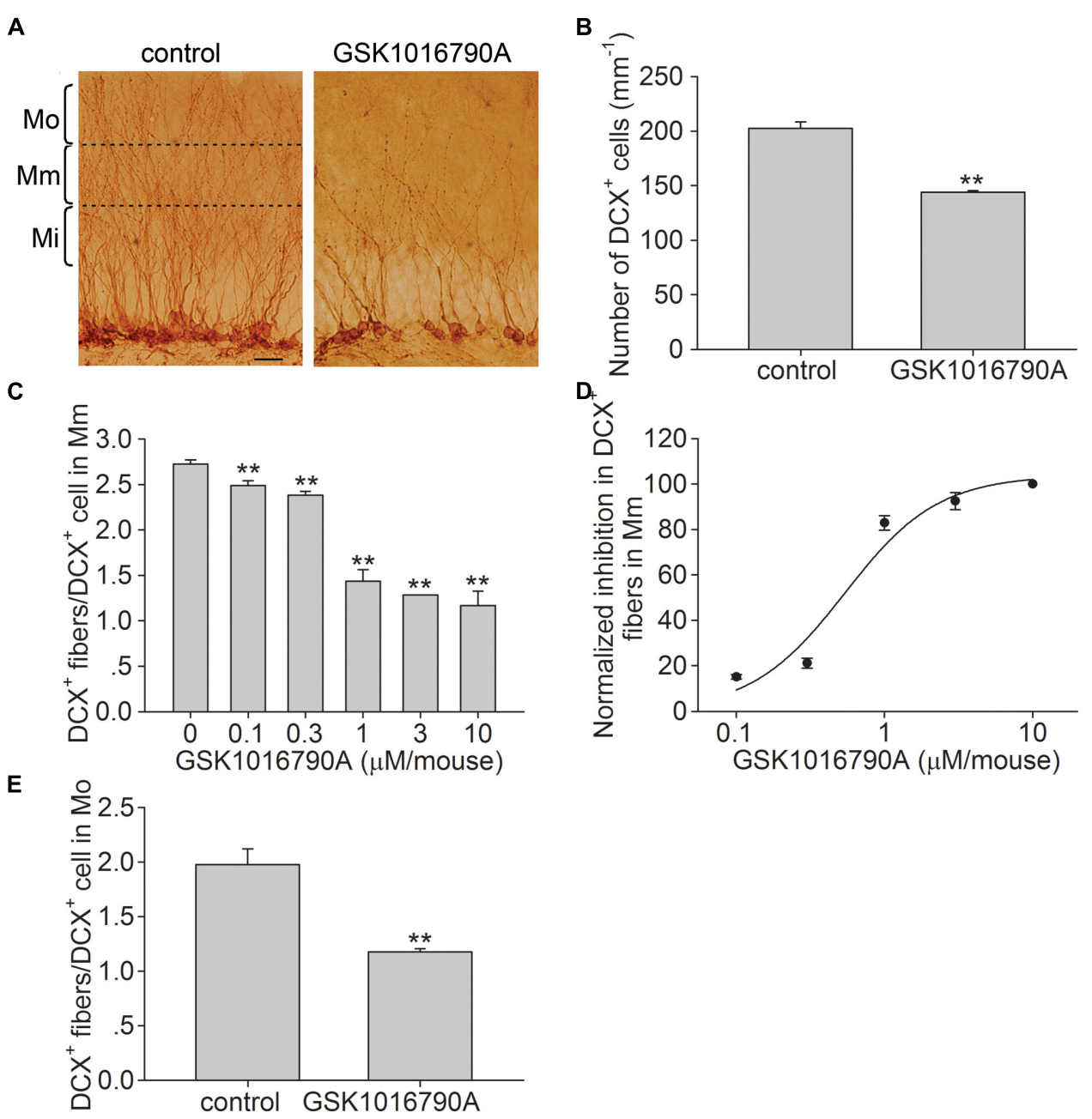

FIGURE 1 | Effect of the TRPV4 activation on the dendritic arborization of newborn cells in the hippocampal DG. (A) Representative pictures of the DCX immunostaining in the hippocampal DG in the control and GSK1016790A-injected mice (GSK1016790A: $1 \mu$ M/mouse). The molecular layer of the DG was divided into the inner (Mi), middle (Mm), and outer (Mo) subregions. Scale bar $=25 \mu \mathrm{m}$. (B) The bar graph shows that the number of DCX+ cells was reduced by GSK1016790A treatment. (C) The bar graph shows DCX+ fibers in the Mm subregion of the DG decreased in the presence of different doses of GSK1016790A. (D) The dose-dependence curve for the GSK1016790A-induced decrease in DCX+ fibers in the Mm subregion. (E) The bar graph shows that the number DCX+ fibers in the Mo subregion was decreased by GSK1016790A (1 $\mu \mathrm{M} / \mathrm{mouse})$. ${ }^{* *} p<0.01 \mathrm{vs}$. control mice.

(Figures 4B,C). Here, the GSK1016790A-induced increase in the p-GSK3 $\beta$, p-MAP2 and p-CRMP-2 protein levels were markedly attenuated by 740 Y-P or CC (Figure 4).

\section{Involvement of the AMPK and Akt Signaling Pathways in the TRPV4 Activation-Induced Inhibition of the Dendritic Arborization of Newborn Neurons in the Hippocampal DG}

As shown in Figure 5, the number of $\mathrm{DCX}^{+}$cells in the SGZ was markedly higher in mice co-injected with GSK1016790A and CC or 740 Y-P than in mice injected with GSK1016790A alone ( $p<0.01$ in each group). $\mathrm{DCX}^{+}$fibers in Mm and Mo increased markedly in the mice that were co-injected with GSK1016790A and CC or 740 Y-P, and the values were markedly different from those in mice that were injected with GSK1016790A alone $(p<0.01$ in each group). By contrast, the numbers of $\mathrm{DCX}^{+}$cells and $\mathrm{DCX}^{+}$fibers in the $\mathrm{Mm}$ and Mo subregions in GSK1016790A-injected mice were nearly the same as those in the mice that were co-injected with GSK1016790A and AICAR. Our data suggest that the activation of AMPK and inhibition of the Akt signaling pathway are likely involved in the TRPV4-induced decrease of newborn neurons and the impairment of dendritic arborization of newly generated neurons.

\section{DISCUSSION}

Neurite growth is a critical process of neurogenesis. Newborn neurons extend axonal and dendritic projections and establish new synaptic connections to the existing hippocampal circuitry 
A

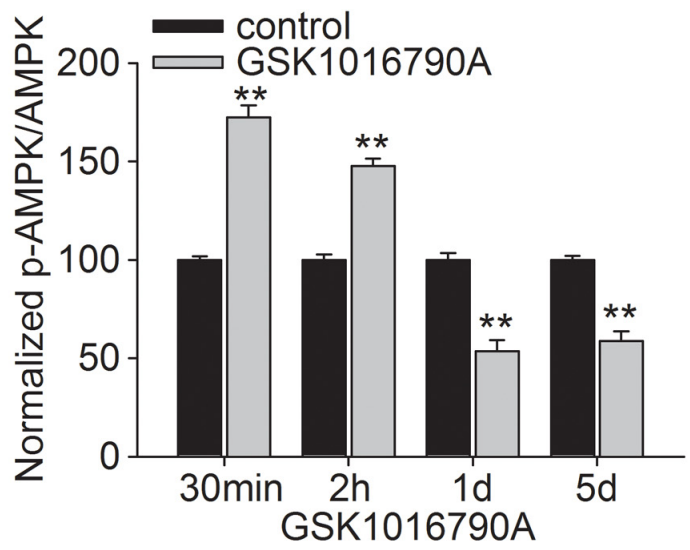

B

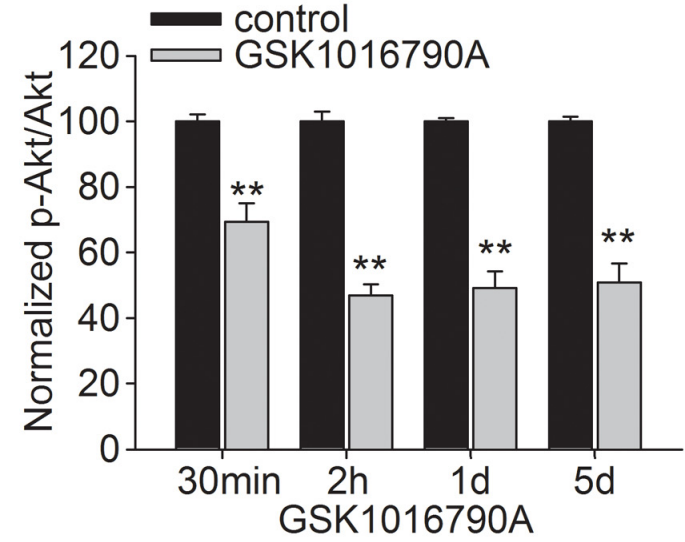

C

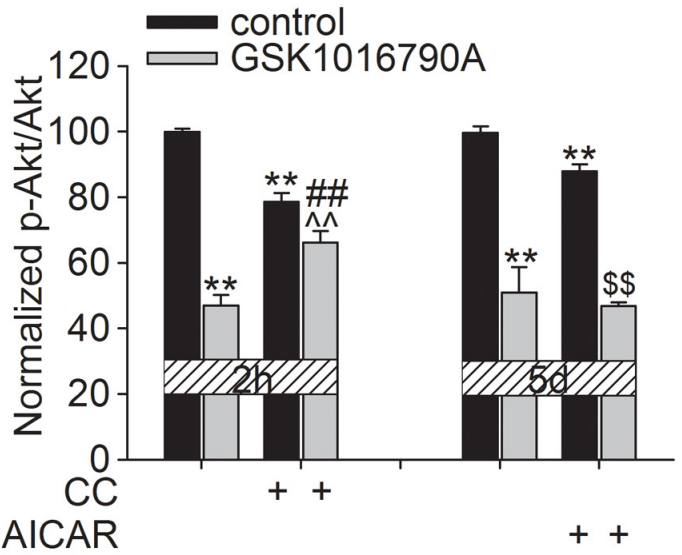

$2 \mathrm{~h}$

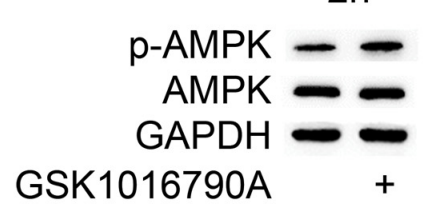

$5 d$

$2 \mathrm{~h}$
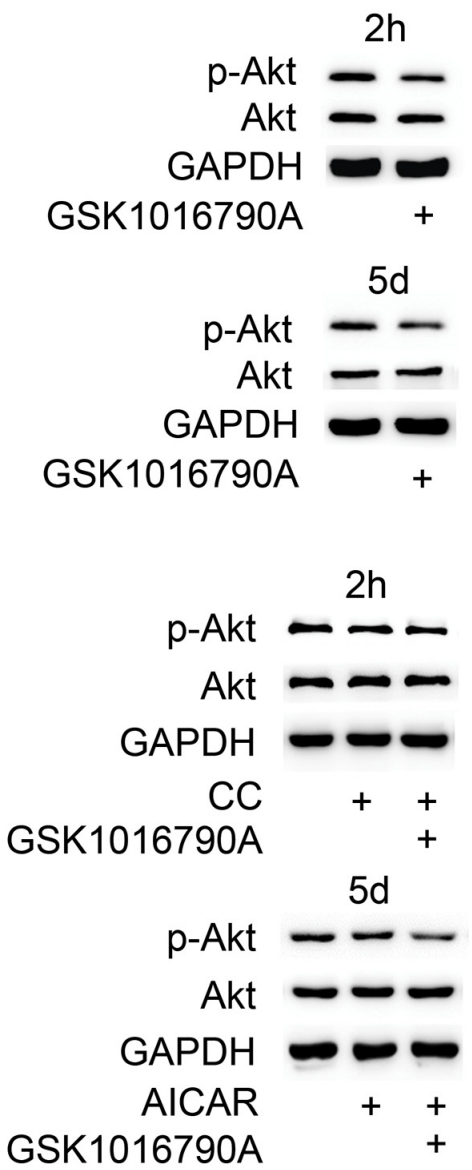

FIGURE 2 Effect of TRPV4 activation on the p-AMPK and p-Akt protein levels. (A,B) Western blot analysis of the hippocampal p-AMPK (A) and p-Akt (B) protein levels at 30 min, $2 \mathrm{~h}, 1$ and 5 days after GSK1016790A injection. (C) The decreased p-Akt protein level at $2 \mathrm{~h}$ after GSK1016790A injection was rescued by the AMPK antagonist CC. The decreased $p$-Akt protein level at 5 days after GSK1016790A injection was not affected by the AMPK agonist AICAR. ${ }^{* *} p<0.01$ vs. control mice, $\# \# p<0.01$ vs. GSK1016790A, ${ }^{m} p<0.01$ vs. CC, $\$ \$ p<0.01$ vs. AICAR.

(Alvarez-Buylla and Garcia-Verdugo, 2002; Zhao et al., 2006). $\mathrm{Ca}^{2+}$ has been proven to be an important regulator of neurite growth. Axon outgrowth and dendritic development occur within the optimal $\left[\mathrm{Ca}^{2+}\right]_{i}$ level, and this process may be inhibited when the $\left[\mathrm{Ca}^{2+}\right]_{i}$ level is below or above this optimal
$\left[\mathrm{Ca}^{2+}\right]_{\mathrm{i}}$ level (Mattson, 1987; Redmond and Ghosh, 2005; Zheng, 2007). As $\mathrm{Ca}^{2+}$-permeable channels, some TRP family members induce $\mathrm{Ca}^{2+}$ influx, leading to increases in $\left[\mathrm{Ca}^{2+}\right]_{\mathrm{i}}$. Accordingly, these channels have been shown to play a role in modulating neurite growth (Benemei et al., 2015). For example, TRPC5 


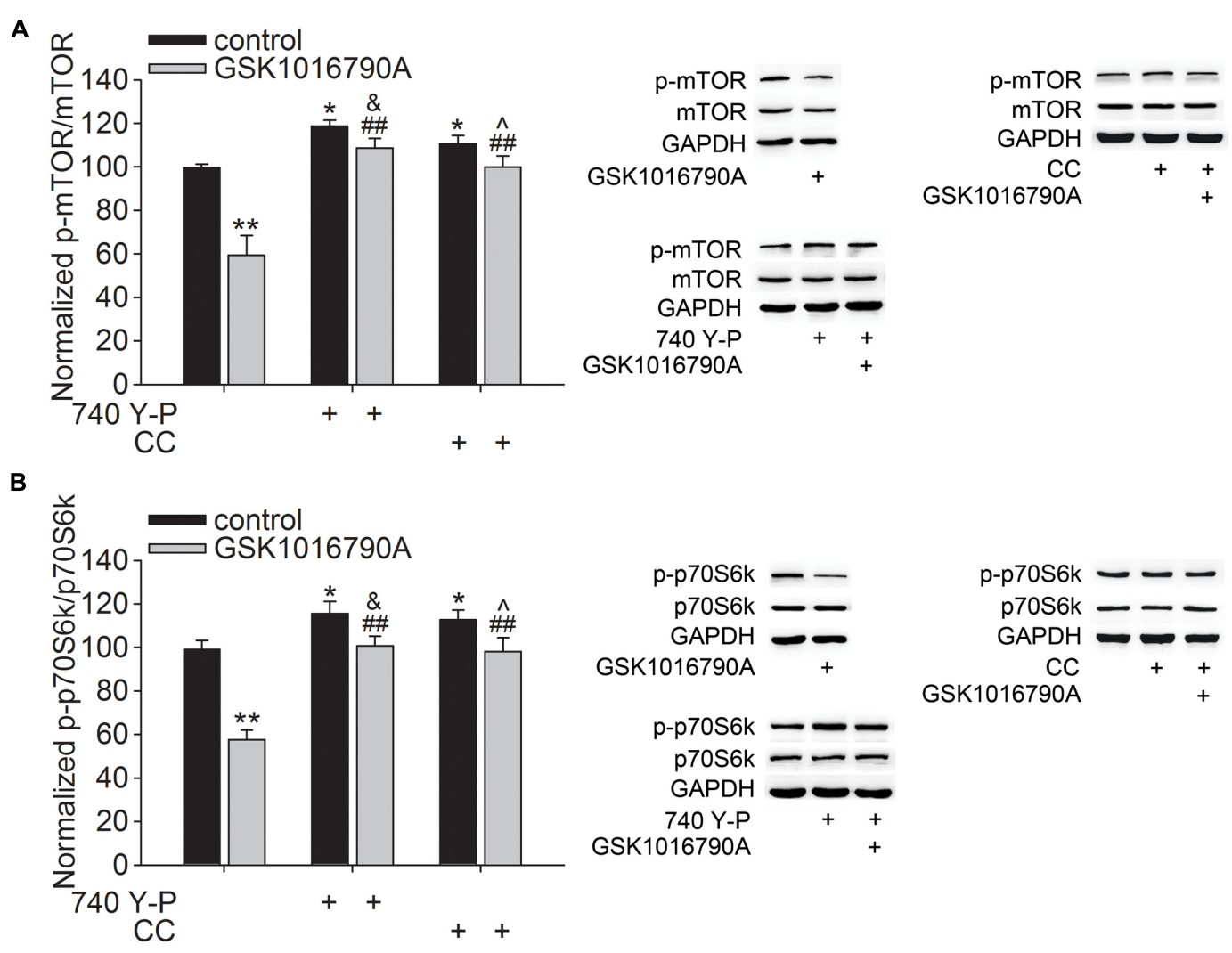

FIGURE 3 | Effect of TRPV4 activation on the p-mTOR and p-p70s6k protein levels. Western blot analysis of the hippocampal p-mTOR (A) and p-p70S6k (B) protein levels in the control and GSK1016790A-injected mice. Note that the GSK1016790A-induced decreases in the p-mTOR (A) and p-p70S6k (B) protein levels were markedly attenuated by the PI3K agonist 740 Y-P or the AMPK antagonist CC. ${ }^{*} p<0.05,{ }^{* *} p<0.01$ vs. control mice, ${ }^{\# \#} p<0.01$ vs. GSK1016790A, $\&_{p}<0.05$ vs. 740 Y-P, $\hat{p}<0.05$ vs. CC.

participates in controling hippocampal neurite length and growth cone morphology, and activation of TRPC5 inhibits neurite extension as well as a rapid vesicular trafficking mechanism regulated by growth factors (Greka et al., 2003; Hui et al., 2006). Inhibition of TRPM2 markedly increases axonal growth, whereas over-expression of it inhibits axonal growth (Jang et al., 2014). Blockage of TRPV1 promotes neurite outgrowth after sciatic nerve injury (Ren et al., 2015). However, activation of TRPV2 leads to axon outgrowth in the developing dorsal root ganglion and motor neurons (Cohen et al., 2015). A gainof-function of TRPV4 mutation increased its $\mathrm{Ca}^{2+}$ channel activity, which underlies the pathogenesis of TRPV4-linked axonal neuropathies (Fecto et al., 2011). Activation of TRPV4 may increase the $\left[\mathrm{Ca}^{2+}\right]_{i}$ in hippocampal neurons (Shibasaki et al., 2007). In this study, $\mathrm{DCX}^{+}$fibers was expressed as $\mathrm{DCX}^{+}$ fibers $/ \mathrm{DCX}^{+}$cell and $\mathrm{DCX}^{+}$fibers in $\mathrm{Mm}$ and Mo subregions were reduced by TRPV4 agonist (Figure 1), suggesting that the density and length of dendrite fibers per newborn neuron were impaired by TRPV4 activation. We previously reported that application of GSK1016790A did not affect the number of DCX ${ }^{+}$ fibers (Tian et al., 2016). In our previous study, GSK1016790A was consecutively injected for 5 days and DCX staining was performed 14 days after the last GSK1016790A injection (Tian et al., 2016). In this case, GSK1016790A was supposed to be absent 7 days after injection and the result that GSK1016790A had no effect on $\mathrm{DCX}^{+}$fibers may not truly reflect the direct effect of TRPV4 activation on the dendritic arborization of newborn neurons. In this study, DCX staining was performed on the same day of the last GSK1016790A injection, and therefore, this inconsistency about the effect of TRPV4 activation on the $\mathrm{DCX}^{+}$fibers is likely due to the difference in drug application protocols between the present and previous studies (Tian et al., 2016).

Akt is a key mediator of several aspects of neurite outgrowth, including elongation, branching and caliber (Read and Gorman, 2009). Previous reports from our group showed that activation of TRPV4 reduced the phosphorylation of Akt (Jie et al., 2015, 2016; Hong et al., 2016). AMPK is a serine/threonine kinase that functions as an important sensor in energy homeostasis in mammalian cells. In addition to an increased ratio of intracellular AMP to ATP, $\mathrm{Ca}^{2+} /$ calmodulin-dependent protein kinase kinase$\beta$ can also activate AMPK in response to an increased $\left[\mathrm{Ca}^{2+}\right]_{i}$ (Hawley et al., 2005). We recently reported that acute application of a TRPV4 agonist caused an increase in the phosphorylation of AMPK, which was related to the TRPV4-mediated $\mathrm{Ca}^{2+}$ influx (Hong et al., 2016). AMPK has been shown to inhibit 
A
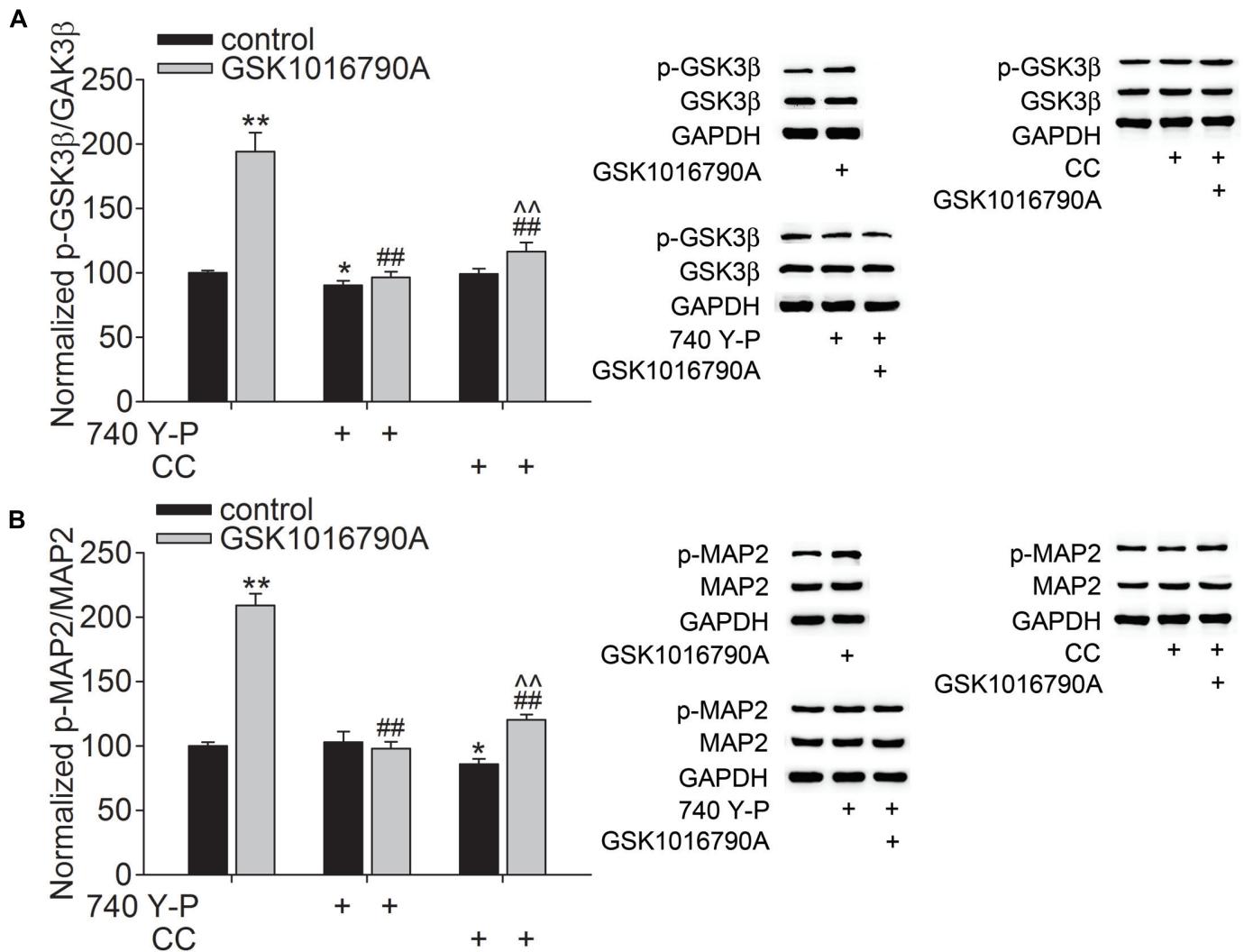

C

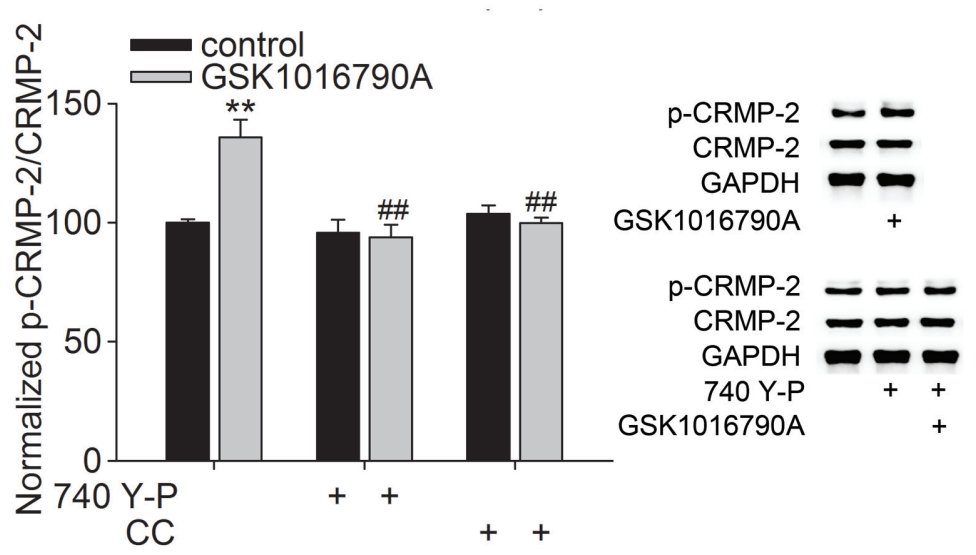

FIGURE 4 | Effect of TRPV4 activation on the p-GSK3 $\beta$, p-MAP2 and p-CRMP-2 protein levels. Western blot analysis of the hippocampal p-GSK3 3 (A) and p-MAP2 (B) and p-CRMP-2 (C) protein levels in the control and GSK1016790A-injected mice. Note that the GSK1016790A-induced increases in p-GSK3 (A) and p-MAP2 (B) and p-CRMP-2 (C) protein levels were markedly attenuated by the PI3K agonist $740 \mathrm{Y}$-P or the AMPK antagonist CC. ${ }^{*} p<0.05,{ }^{* *} p<0.01$ vs. control mice, $\# \# p<0.01$ vs. GSK1016790A, ${ }^{m} p<0.01$ vs. CC.

neuronal development at multiple stages, during both axon outgrowth and dendrite growth and arborization (Ramamurthy et al., 2014). Activation of AMPK pathway can suppress axon initiation and neuronal polarization through interfering with PI3K signaling (Amato et al., 2011; Amato and Man, 2012). Application of AMPK antagonist CC promotes the dopaminergic dendrite outgrowth (Wakita et al., 2014). These reports prompted us to study whether the AMPK and Akt signaling pathways were involved in the TRPV4-induced inhibition of the dendritic arborization of newborn neurons. Here, we first examined the phosphorylation of AMPK and Akt at different time points after GSK1016790A treatment. The present results showed that the AMPK activity increased within $2 \mathrm{~h}$ and then decreased from 1 to 5 days after the beginning of the experiment, whereas the Akt activity consistently decreased from $30 \mathrm{~min}$ to 5 days after the beginning of the experiment. Notably, the decrease in the p-Akt protein level in GSK1016790A-injected mice was markedly blocked by the AMPK antagonist CC, but it was unaffected by the 

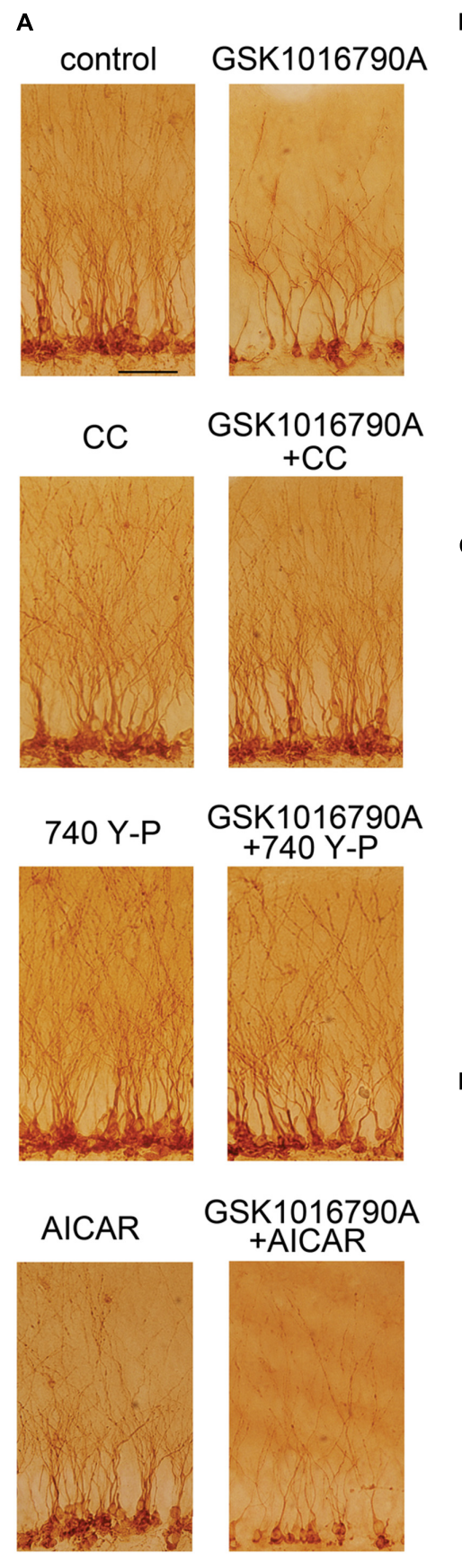

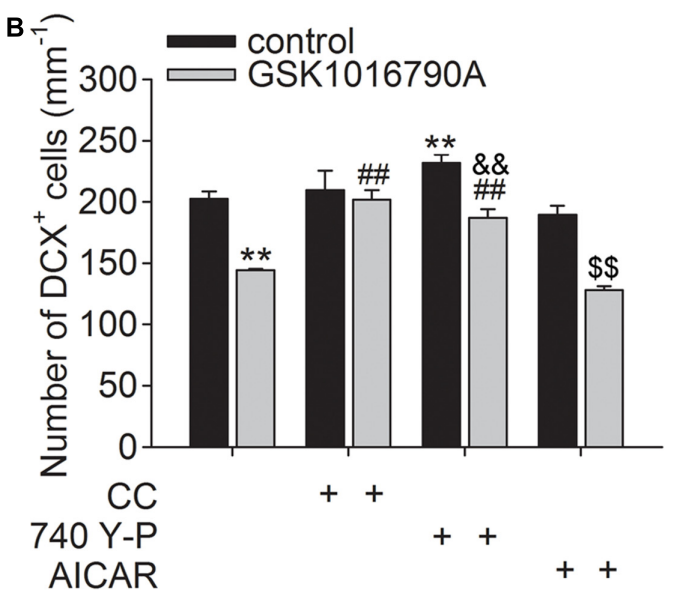

C
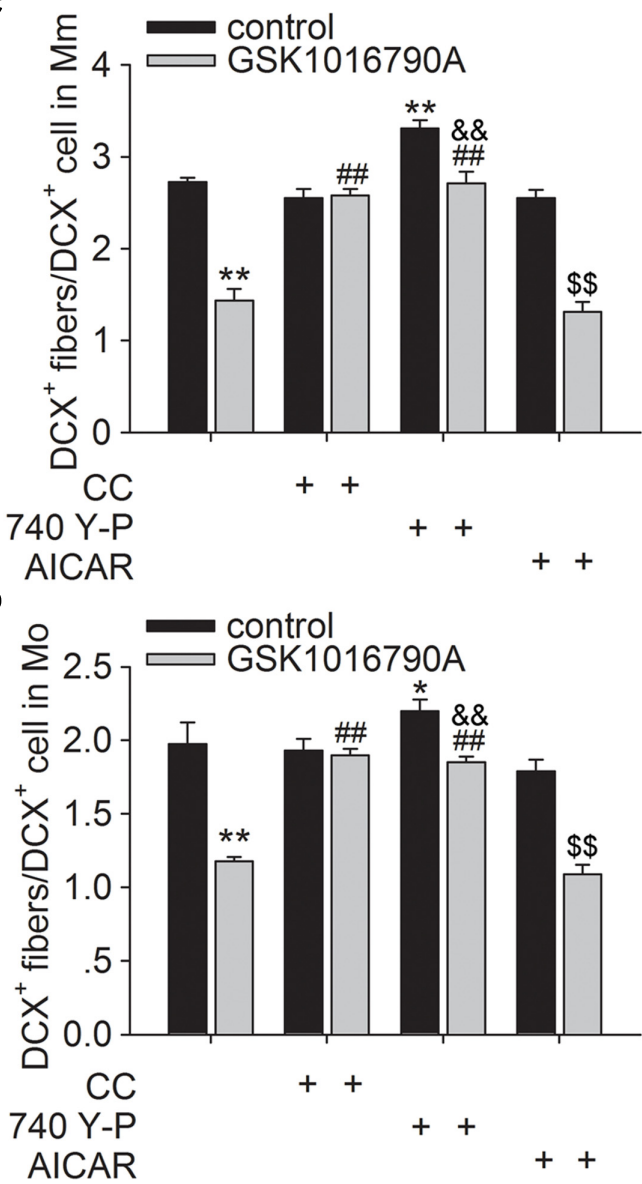

FIGURE 5 | Involvement of the AMPK and Akt signaling in the TRPV4 activation-induced impairment of dendritic arborization. DCX immunostaining (A) and the bar graph show that GSK1016790A-induced decreases in DCX+ cells (B) and DCX+ fibers in the Mm (C) and Mo (D) subregions were attenuated by CC (AMPK antagonist) and 740 Y-P (PI3K agonist), but were unaffected by AICAR (AMPK agonist). ${ }^{*} p<0.05,{ }^{* *} p<0.01$ vs. control mice, \#\#p<0.01 vs. GSK1016790A, $\& \& p<0.01$ vs. 740 Y-P, $\$ \$ p<0.01$ vs. AICAR

AMPK activator AICAR (Figure 2). Therefore, during chronic TRPV4 activation, the initial activation of AMPK is probably responsible for the inhibition of Akt signaling. We also found that the GSK1016790A-induced decrease of $\mathrm{DCX}^{+}$cells and $\mathrm{DCX}^{+}$ fibers was markedly blocked by the PI3K agonist $740 \mathrm{Y}-\mathrm{P}$ or by
AMPK antagonist CC. By contrast, the application of AMPK agonist AICAR did not have a similar effect in GSK1016790Ainjected mice (Figure 5). Akt signaling also plays an important role in neuronal survival and previous studies show that activation of TRPV4 results in neuronal death, which is mediated, 


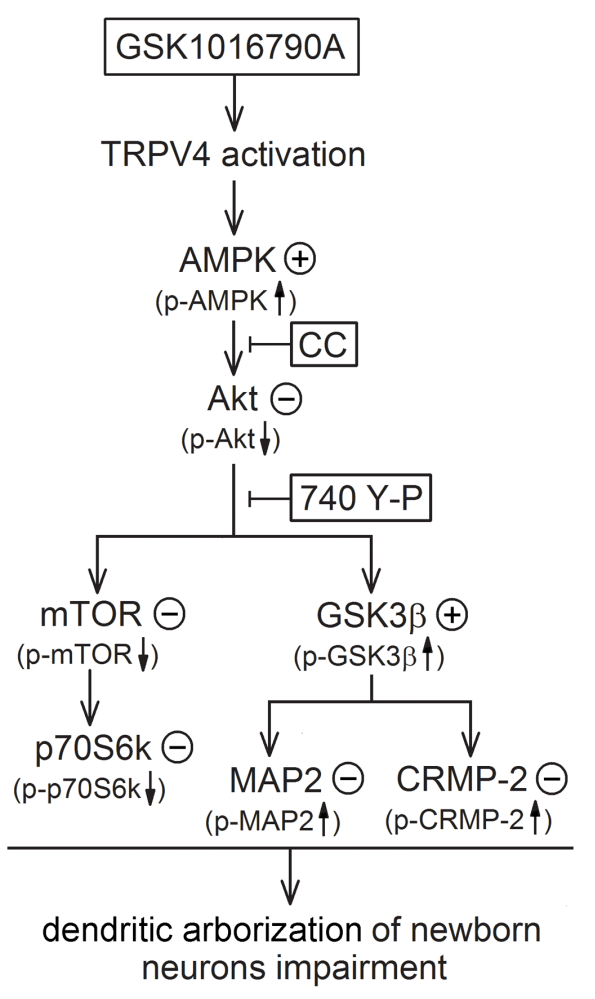

GSK $1016790 \mathrm{~A}:$ TRPV4 agonist; CC: AMPK antagonist 740 Y-P: PI3K agonist

$\oplus$ : activity increase; $\oplus$ : activity decrease

$\uparrow$ : protein level increase; $\downarrow$ : protein level decrease

FIGURE 6 | Possible mechanisms underlying TRPV4 activation-induced impairment of dendritic arborization of newborn neurons. Activation of TRPV4 impairs the dendritic arborization of newborn neurons in the adult hippocampl DG and this effect is dependent on increasing AMPK activity and inhibiting Akt. The inhibited Akt leads to down-regulate mTOR-p70S6k signaling and increase of GSK3 $\beta$ activity; the increased GSK3 $\beta$ activity results in inhibition of MAP2 and CRMP-2 function ultimately.

at least partially, by inhibiting Akt signaling (Luo et al., 2003; Jie et al., 2015, 2016). Therefore, our findings suggest that AMPK activation and the related down-regulation of Akt signaling are involved in the TRPV4-induced decrease of newborn neurons and the dendritic arborization of single neuron. Nevertheless, it was still unclear how AMPK activity was subsequently inhibited when TRPV4 was chronically activated. A previous study showed that activation of extracellular signal-regulated kinase $1 / 2($ ERK1/2) is responsible for dephosphorylation of AMPK at $\mathrm{Thr}^{172}$ caused by $\alpha$ - melanocyte-stimulating hormone (Damm et al., 2012). Of note, activation of TRPV4 has been proven to increase ERK1/2 activity (Jie et al., 2015; Tian et al., 2016). More experiments are needed to clarify whether the enhanced ERK1/2 is involved in the decrease in AMPK activity during the later stage of TRPV4 activation. The present data showed that the TRPV4induced decrease in the p-Akt protein level was not affected by AICAR, indicating that other factors contribute to the inhibition of Akt signaling during chronic TRPV4 activation.
Mammalian target of rapamycin and GSK3 $\beta$, two major substrates that are downstream of Akt, have been identified to play key roles in Akt-mediated neurite growth (Read and Gorman, 2009). Activation of the PI3K-Akt-mTOR signaling pathway can phosphorylate p70S6k, which plays a fundamental role in axonal and dendritic growth. In cultured hippocampal neurons, the dendritic complexity was reduced by inhibition of PI3K and knockdown of mTOR or p70S6k (Jaworski et al., 2005). In AD model mice, the neurite growth of newborn neurons in the hippocampal DG is impaired with reduced phosphorylation of Akt and mTOR (Li L. et al., 2010). Here, decreased p-mTOR and p-p70S6k protein levels were found in GSK1016790A-injected mice, and this inhibitory effect caused by TRPV4 activation was markedly blocked by 740 Y-P or CC (Figure 3). Together with the above discussion, these results indicate that activation of TRPV4 may increase AMPK activity and then lead to inhibition of PI3K-Akt-mTOR-p70S6k signaling pathway. GSK3 $\beta$ has been proven to play an important role in neuronal morphogenesis. GSK3 $\beta$ activity is inversely correlated with PI3K-Akt signaling activity (Cross et al., 1995). One of the downstream targets of GSK3 $\beta$ is MAP2, which is important for microtubule polymerization and dendrite elongation (Sánchez et al., 2000; Lim and Walikonis, 2008). Phosphorylation of MAP2 causes it to lose its ability to effectively associate with the microtubules. Akt activation was shown to inactivate GSK3 $\beta$ and consequently reduce phosphorylation of MAP2, which can promote microtubule polymerization and dendrite elongation (Lim and Walikonis, 2008). Another important downstream target of GSK3 $\beta$ is CRMP-2 that is critical for promoting axon specification and neurite extension through reorganization of actin filaments, regulation of microtubule assembly, endocytosis of adhesion molecules and also axonal protein trafficking (Yoshimura et al., 2005, 2006). GSK3 $\beta$ phosphorylates CRMP-2 to decreases its tubulin heterodimer binding ability (Yoshimura et al., 2005, 2006). In the present study, the p-GSK3 $\beta\left(Y^{216}\right)$ protein level increased significantly in GSK1016790A-injected mice, indicating higher activity of GSK3 $\beta$ upon TRPV4 activation (Bhat et al., 2000). In addition to the increased p-GSK3 $\beta$ protein level, the p-MAP2 and p-CRMP-2 protein levels were increased by GSK1016790A treatment, indicating a decrease in the MAP2 and CRMP-2 function upon TRPV4 activation (Figure 4). Here, the increase in the p-GSK3 $\beta\left(\mathrm{Y}^{216}\right)$, p-MAP2 and p-CRMP-2 protein levels was markedly lower in the mice that were co-injected with GSK1016790A and 740 Y-P or and CC (Figure 4); this finding indicates that activation of TRPV4 may increase AMPK activity to down-regulate PI3K-Akt signaling, then increase GSK3 $\beta$ activity, and ultimately decrease MAP2 and CRMP-2 function.

The present results suggest that activation of AMPK and inhibition of Akt signaling are likely responsible for TRPV4induced impairment of dendritic arborization of newborn neurons, which is mediated by downstream substrates of Akt, including mTOR and GSK3 $\beta$ (Figure 6). In this study, we did not provide the direct evidence for TRPV4 activation-induced modulation of axon outgrowth. Concerning the important role of AMPK, Akt and the related substrates in the modulation of axonogenesis, the activation of AMPK and the down-regulation 
of Akt signaling provide a possibility that the axon outgrowth of newborn neurons may be impaired by TRPV4 activation. More experiments are needed to prove this speculation. Here it is noted that besides the decrease of $\mathrm{DCX}^{+}$fibers, the number of $\mathrm{DCX}^{+}$cells was also reduced by activation of TRPV4. It has been reported that apoptosis of newborn cells occurs during adult neurogenesis (Sierra et al., 2010). In our previous study, the inhibited Akt signaling is involved in TRPV4 activation-induced apoptosis and therefore this action may be a reason for the present decreased $\mathrm{DCX}^{+}$cells (Jie et al., 2015). Neurite growth is important for the survival of newborn neurons and impaired neurite growth may result in a decline of newborn neurons in the pathological condition (Li L. et al., 2010). In the present study, we did not examine the dying process of $\mathrm{DCX}^{+}$cells upon TRPV4 activation, but the present reduced $\mathrm{DCX}^{+}$fibers indicates that these newborn neurons were already "unhealthy" cells and their subsequent survival might be impaired. Collectively, TRPV4 activation-induced impairment of dendrite morphology may result from the decreased newborn neurons and the impairment of dendritic arborization of single neuron. As a $\mathrm{Ca}^{2+}$-permeable channel, TRPV4 may be a new potential target for modulating

\section{REFERENCES}

Alvarez-Buylla, A., and Garcia-Verdugo, J. M. (2002). Neurogenesis in adult subventricular zone. J. Neurosci. 22, 629-634.

Amato, S., Liu, X., Zheng, B., Cantley, L., Rakic, P., and Man, H. Y. (2011). AMPactivated protein kinase regulates neuronal polarization by interfering with PI3-kinase localization. Science 332, 247-251. doi: 10.1126/science.1201678

Amato, S., and Man, H. Y. (2012). AMPK signaling in neuronal polarization: putting the brakes on axonal traffic of PI3-kinase. Commun. Integr. Biol. 5, 152-155. doi: $10.4161 /$ cib. 18968

Balu, D. T., and Lucki, I. (2009). Adult hippocampal neurogenesis: regulation, function implications and contribution to disease pathology. Neurosci. Biobehav. Rev. 33, 232-252. doi: 10.1016/j.neubiorev.2008.08.007

Benemei, S., Patacchini, R., Trevisani, M., and Geppetti, P. (2015). TRP channels. Curr. Opin. Pharmacol. 22, 18-23. doi: 10.1016/j.coph.2015.02.006

Bhat, R. V., Shanley, J., Correll, M. P., Fieles, W. E., Keith, R. A., Scott, C. W., et al. (2000). Regulation and localization of tyrosine 216 phosphorylation of glycogen synthase kinase-3beta in cellular and animal models of neuronal degeneration. Proc. Natl. Acad. Sci. U.S.A. 97, 11074-11079. doi: 10.1073/pnas.190297597

Cohen, M. R., Johnson, W. M., Pilat, J. M., Kiselar, J., DeFrancesco-Lisowitz, A., Zigmond, R. E., et al. (2015). Nerve growth factor regulates transient receptor potential vanilloid 2 via extracellular signal-regulated kinase signaling to enhance neurite outgrowth in developing neurons. Mol. Cell. Biol. 35, 4238-4252. doi: 10.1128/MCB.00549-15

Cross, D. A., Alessi, D. R., Cohen, P., Andjelkovich, M., and Hemmings, B. A. (1995). Inhibition of glycogen synthase kinase- 3 by insulin mediated by protein kinase B. Nature 378, 785-789. doi: 10.1038/378785a0

Damm, E., Buech, T. R., and Gudermann, T. (2012). Melanocortin-induced PKA activation inhibits AMPK activity via ERK-1/2 and LKB-1 in hypothalamic GT1-7 cells. Mol. Endocrinol. 26, 643-654. doi: 10.1210/me.2011-1218

Derossi, D., Williams, E. J., Green, P. J., Dunican, D. J., and Doherty, P. (1998). Stimulation of mitogenesis by a cell-permeable PI 3-kinase binding peptide. Biochem. Biophys. Res. Commun. 251, 148-152. doi: 10.1006/bbrc.1998.9444

Duan, X., Kang, E., Liu, C. Y., Ming, G. L., and Song, H. (2008). Development of neural stem cell in the adult brain. Curr. Opin. Neurobiol. 18, 108-115. doi: 10.1016/j.conb.2008.04.001

Fecto, F., Shi, Y., Huda, R., Martina, M., Siddique, T., and Deng, H. X. (2011). Mutant TRPV4-mediated toxicity is linked to increased constitutive function in axonal neuropathies. J. Biol. Chem. 286, 17281-17291. doi: 10.1074/jbc.M111. 237685 neurite growth. The present study also provides more evidence that TRPV4 activation probably plays an important role in the modulation of several processes of adult hippocampal neurogenesis.

\section{AUTHOR CONTRIBUTIONS}

YT, MQ, ZW, and SS performed experiments; CW, ZS, and YL analyzed data; LeC designed experiments and wrote the article; YD and LiC revised the manuscript and all authors approved the final version.

\section{ACKNOWLEDGMENTS}

This work was supported by National Natural Science Foundation of China (81571270), Qing Lan Project of Jiangsu Province (2014-2017) and 13th Six Talents Peak Project of Jiangsu Province (JY-049) to LeC, National Natural Science Foundation of China (81470421) to YD, and National Natural Science Foundation of China (31600835) to SS.

Ge, S., Sailor, K. A., and Ming, G. L. (2008). Synaptic integration and plasticity of new neurons in the adult hippocampus. J. Physiol. 586, 3759-3765. doi: 10.1113/jphysiol.2008.155655

Greka, A., Navarro, B., Oancea, E., Duggan, A., and Clapham, D. E. (2003). TRPC5 is a regulator of hippocampal neurite length and growth cone morphology. Nat. Neurosci. 6, 837-845. doi: 10.1038/nn1092

Han, S. M., Namkoong, C., Jang, P. G., Park, I. S., Hong, S. W., Katakami, H., et al. (2005). Hypothalamic AMP-activated protein kinase mediates counterregulatory responses to hypoglycaemia in rats. Diabetologia 48, 2170-2178. doi: 10.1007/s00125-005-1913-1

Hawley, S. A., Pan, D. A., Mustard, K. J., Ross, L., Bain, J., Edelman, A. M., et al. (2005). Calmodulin-dependent protein kinase kinase-beta is an alternative upstream kinase for AMP-activated protein kinase. Cell Metab. 2, 9-19. doi: 10.1016/j.cmet.2005.05.009

Hong, Z., Tian, Y., Qi, M., Li, Y., Du, Y., Chen, L., et al. (2016). Transient receptor potential vanilloid 4 inhibits $\gamma$-aminobutyric acid-activated current in hippocampal pyramidal neurons. Front. Mol. Neurosci. 9:77. doi: 10.3389/ fnmol.2016.00077

Hui, H., McHugh, D., Hannan, M., Zeng, F., Xu, S. Z., Khan, S. U., et al. (2006). Calcium-sensing mechanism in TRPC5 channels contributing to retardation of neurite outgrowth. J. Physiol. 57, 165-172. doi: 10.1113/jphysiol.2005.102889

Jang, Y., Jung, J., Kim, H., Oh, J., Jeon, J. H., Jung, S., et al. (2012). Axonal neuropathy-associated TRPV4 regulates neurotrophic factor-derived axonal growth. J. Biol. Chem. 2287, 6014-6024. doi: 10.1074/jbc.M111.316315

Jang, Y., Lee, M. H., Lee, J., Jung, J., Lee, S. H., Yang, D. J., et al. (2014). TRPM2 mediates the lysophosphatidic acid-induced neurite retraction in the developing brain. Pflugers Arch. 466, 1987-1998. doi: 10.1007/s00424-0131436- 4

Jaworski, J., Spangler, S., Seeburg, D. P., Hoogenraad, C. C., and Sheng, M. (2005). Control of dendritic arborization by the phosphoinositide-3'-kinaseAkt-mammalian target of rapamycin pathway. J. Neurosci. 25, 11300-11312. doi: 10.1523/JNEUROSCI.2270-05.2005

Jie, P., Hong, Z., Tian, Y., Li, Y., Lin, L., Zhou, L., et al. (2015). Activation of transient receptor potential vanilloid 4 induces apoptosis in hippocampus through downregulating PI3K/Akt and upregulating p38 MAPK signaling pathways. Cell Death Dis. 6, e1775. doi: 10.1038/cddis.2015.146

Jie, P., Lu, Z., Hong, Z., Li, L., Zhou, L., Li, Y., et al. (2016). Activation of transient receptor potential vanilloid 4 is involved in neuronal injury in middle cerebral artery occlusion in mice. Mol. Neurobiol. 53, 8-17. doi: 10.1007/s12035-0148992-2 
Li, J., Benashski, S. E., Siegel, C., Liu, F., and McCullough, L. D. (2010). Adenosine monophosphate activated protein kinase inhibition is protective in both sexes after experimental stroke. Neurosci. Lett. 482, 62-65. doi: 10.1016/j.neulet.2010. 07.007

Li, L., Xu, B., Zhu, Y., Chen, L., Sokabe, M., and Chen, L. (2010). DHEA prevents A 325 -35-impaired survival of newborn neurons in the dentate gyrus through a modulation of PI3K-Akt-mTOR signaling. Neuropharmacology 59, 323-333. doi: 10.1016/j.neuropharm.2010.02.009

Lim, C. S., and Walikonis, R. S. (2008). Hepatocyte growth factor and c-Met promote dendritic maturation during hippocampal neuron differentiation via the Akt pathway. Cell. Signal. 20, 825-835. doi: 10.1016/j.cellsig.2007.12.013

Liu, F., Benashski, S. E., Persky, R., Xu, Y., Li, J., and McCullough, L. D. (2012). Agerelated changes in AMP-activated protein kinase after stroke. Age 34, 157-168. doi: 10.1007/s11357-011-9214-8

Luo, H. R., Hattori, H., Hossain, M. A., Hester, L., Huang, Y., Lee-Kwon, W., et al. (2003). Akt as a mediator of cell death. Proc. Natl. Acad. Sci. U.S.A. 100, 11712-11717. doi: 10.1073/pnas.1634990100

Mattson, M. P. (1987). Calcium regulation of neurite elongation and growth cone motility. J. Neurosci. 7, 4034-4043.

Nacher, J., and McEwen, B. S. (2006). The role of N-methyl-D-asparate receptors in neurogenesis. Hippocampus 16, 267-270. doi: 10.1002/hipo.20160

Nordman, J. C., Phillips, W. S., Kodama, N., Clark, S. G., Del Negro, C. A., and Kabbani, N. (2014). Axon targeting of the alpha 7 nicotinic receptor in developing hippocampal neurons by Gprin1 regulates growth. J. Neurochem. 129, 649-662. doi: 10.1111/jnc.12641

Pankratov, Y., and Lalo, U. (2014). Calcium permeability of ligand-gated $\mathrm{Ca}^{2+}$ channels. Eur. J. Pharmacol. 739, 60-73. doi: 10.1016/j.ejphar.2013.11.017

Ramamurthy, S., Chang, E., Cao, Y., Zhu, J., and Ronnett, G. V. (2014). AMPK activation regulates neuronal structure in developing hippocampal neurons. Neuroscience 259, 13-24. doi: 10.1016/j.neuroscience.2013.11.048

Rao, M. S., and Shetty, A. K. (2004). Efficacy of doublecortin as a marker to analyse the absolute number and dendritic growth of newly generated neurons in the adult dentate gyrus. Eur. J. Neurosci. 19, 234-246. doi: 10.1111/j.0953-816X. 2003.03123.x

Read, D. E., and Gorman, A. M. (2009). Involvement of Akt in neurite outgrowth. Cell. Mol. Life Sci. 66, 2975-2984. doi: 10.1007/s00018-0090057-8

Redmond, L., and Ghosh, A. (2005). Regulation of dendritic development by calcium signaling. Cell Calcium 37, 411-416. doi: 10.1016/j.ceca.2005. 01.009

Ren, F., Zhang, H., Qi, C., Gao, M. L., Wang, H., and Li, X. Q. (2015). Blockade of transient receptor potential cation channel subfamily $\mathrm{V}$ member 1 promotes regeneration after sciatic nerve injury. Neural Regen. Res. 10, 1324-1331. doi: 10.4103/1673-5374.162770

Sánchez, C., Díaz-Nido, J., and Avila, J. (2000). Phosphorylation of microtubuleassociated protein 2 (MAP2) and its relevance for the regulation of the neuronal cytoskeleton function. Prog. Neurobiol. 61, 133-168. doi: 10.1016/ S0301-0082(99)00046-5

Sha, S., Qu, W. J., Li, L., Lu, Z. H., Chen, L., Yu, W. F., et al. (2013). Sigma-1 receptor knockout impairs neurogenesis in dentate gyrus of adult hippocampus via down-regulation of NMDA receptors. CNS Neurosci. Ther. 19, 705-713. doi: $10.1111 / \mathrm{cns} .12129$

Shibasaki, K., Suzuki, M., Mizuno, A., and Tominaga, M. (2007). Effects of body temperature on neural activity in the hippocampus: regulation of resting membrane potentials by transient receptor potential vanilloid 4. J. Neurosci. 27, 1566-1575. doi: 10.1523/JNEUROSCI.4284-06.2007

Sierra, A., Encinas, J. M., Deudero, J. J., Chancey, J. H., Enikolopov, G., OverstreetWadiche, L. S., et al. (2010). Microglia shape adult hippocampal neurogenesis through apoptosis-coupled phagocytosis. Cell Stem Cell 7, 483-495. doi: 10.1016/j.stem.2010.08.014

Sygnecka, K., Heine, C., Scherf, N., Fasold, M., Binder, H., Scheller, C., et al. (2015). Nimodipine enhances neurite outgrowth in dopaminergic brain slice co-cultures. Int. J. Dev. Neurosci. 40, 1-11. doi: 10.1016/j.ijdevneu.2014. 10.005

Tang, F., and Dent, E. W. (2003). Spontaneous calcium transients in developing cortical neurons regulate axon outgrowth. J. Neurosci. 23, 927-936.

Tian, Y., Qi, M., Hong, Z., Li, Y., Yuan, Y., Du, Y., et al. (2016). Activation of transient receptor potential vanilloid 4 promotes the proliferation of stem cells in the adult hippocampal dentate gyrus. Mol. Neurobiol. doi: 10.1007/s12035016-0113-y [Epub ahead of print].

Toth, A. B., Shum, A. K., and Prakriya, M. (2016). Regulation of neurogenesis by calcium signaling. Cell Calcium 59, 124-134. doi: 10.1016/j.ceca.2016.02.011

Venna, V. R., Li, J., Benashski, S. E., Tarabishy, S., and McCullough, L. D. (2012). Preconditioning induces sustained neuroprotection by downregulation of adenosine 5'-monophosphate-activated protein kinase. Neuroscience 201, 280-287. doi: 10.1016/j.neuroscience.2011.11.014

Vincent, F., and Duncton, M. A. (2011). TRPV4 agonists and antagonists. Curr. Top. Med. Chem. 11, 2216-2226. doi: 10.2174/156802611796904861

Wakita, S., Izumi, Y., Nakai, T., Adachi, K., Takada-Takatori, Y., Kume, T., et al. (2014). Staurosporine induces dopaminergic neurite outgrowth through AMPactivated protein kinase/mammalian target of rapamycin signaling pathway. Neuropharmacology 77, 39-48. doi: 10.1016/j.neuropharm.2013.09.012

Wang, C., Chen, T., Li, G., Zhou, L., Sha, S., and Chen, L. (2015). Simvastatin prevents $\beta$-amyloid(25-35)-impaired neurogenesis in hippocampal dentate gyrus through $\alpha 7 \mathrm{nAChR}$-dependent cascading PI3K-Akt and increasing BDNF via reduction of farnesyl pyrophosphate. Neuropharmacology 97, 122-132. doi: 10.1016/j.neuropharm.2015.05.020

White, J. P., Cibelli, M., Urban, L., Nilius, B., McGeown, J. G., and Nagy, I. (2016). TRPV4: molecular conductor of a diverse Orchestra. Physiol. Rev. 96, 911-973. doi: 10.1152/physrev.00016.2015

Williams, E. J., and Doherty, P. (1999). Evidence for and against a pivotal role of PI 3-kinase in a neuronal cell survival pathway. Mol. Cell. Neurosci. 13, 272-280. doi: 10.1006/mcne.1999.0750

Yoshimura, T., Arimura, N., and Kaibuchi, K. (2006). Signaling networks in neuronal polarization. J. Neurosci. 26, 10626-10630. doi: 10.1523/JNEUROSCI. 3824-06.2006

Yoshimura, T., Kawano, Y., Arimura, N., Kawabata, S., Kikuchi, A., and Kaibuchi, K. (2005). GSK-3beta regulates phosphorylation of CRMP-2 and neuronal polarity. Cell 120, 137-149. doi: 10.1016/j.cell.2004.11.012

Zhao, C., Teng, E. M., Summers, R. G., Ming, G. L., and Gage, F. H. (2006). Distinct morphological stages of dentate granule neuron maturation in the adult mouse hippocampus. J. Neurosci. 26, 3-11. doi: 10.1523/JNEUROSCI.3648-05.2006

Zheng, J. Q. (2007). Calcium signaling in neuronal motility. Annu. Rev. Cell Dev. Biol. 23, 375-404. doi: 10.1146/annurev.cellbio.23.090506.123221

Conflict of Interest Statement: The authors declare that the research was conducted in the absence of any commercial or financial relationships that could be construed as a potential conflict of interest.

Copyright (C) 2017 Tian, Qi, Wang, Wu, Sun, Li, Sha, Du, Chen and Chen. This is an open-access article distributed under the terms of the Creative Commons Attribution License (CC BY). The use, distribution or reproduction in other forums is permitted, provided the original author(s) or licensor are credited and that the original publication in this journal is cited, in accordance with accepted academic practice. No use, distribution or reproduction is permitted which does not comply with these terms. 